\title{
Research of Fuzzy-PID Temperature Control and Mathematical Modeling of Rice germination System Based on Genetic Algorithm
}

\author{
Shi Jianfei \\ College of Information Technology, Heilongjiang Bayi Agricultural University, \\ Daqing 163319, China \\ 526375219@qq.com
}

\begin{abstract}
In the process of the rice germination, temperature control is the key. Due to the accelerating seed germination system belongs to a complex nonlinear, large time delay and multivariable, it is difficult to establish the exact mathematical relationship model. In order to solve this problem, in this paper, we established the model based on RBF neural network, and used genetic algorithm to optimize the parameters of the neural network. In order to realize the accurate control of temperature and ensure the quality of rice sprouting, Fuzzy-PID control method can adjusts the parameters of PID and effectively improve the uniform distribution of temperature in the germinating box. The $3 D$ graphics of temperature distribution obtained by MATLAB can show effectiveness of the method. Finally, the control strategy and system model improving the rice budding rate and evenness of emergence, are verified by experimental verification.
\end{abstract}

Keywords: Rice germination, Fuzzy-PID, RBF, Genetic algorithm

\section{Introduction}

China was the first country in the world to plant rice. In the North of China, Process of rice production includes three stages: germination, greenhouse seedlings and rice transplanting. In the process of the emergence, the uniformity of temperature control is a key. Due to uneven temperature distribution, can cause uneven rice budding and poor quality. The technique for germination is a guarantee of promotion of quality.

The rice production in Chinese northern parts has three stages, mainly including rice germination, sprout cultivation in greenhouse and planting in farm land. The rice germination technology means to improve the guarantee of sprout cultivation. In the past, the technology of traditional local method germination technology was widely used in Heilongjiang province [1-2]. Nowadays, the quality of rice germination were affected by the large area planting of cold area rice in Heilongjiang agricultural areas, which was carried on a work of the rice germination at the end of march in every year [3-4]. And in this period, due to the area is located in the high latitude area, larger temperature difference between day and night, so it is difficult to meet the process requirements of the rice germination temperature. Aiming at the above problems, the mathematical model establishment of the rice germination system has become the main way to improve the control performance of the whole system. In addition, previous studies mainly focused on the control strategy, process improvement and the automated monitoring of the whole system. And the system modeling method was less researched. Because the rice germination system is a complex system which has characters of nonlinear, large time delay and multi variables. So it is difficult to establishment model through the exact mathematical relationship. Thus it is hard to reach the requirements of actual control, despite we have a batter control strategy. We can better complete the establishment of 
mathematical model system by using the learning ability of neural network and the experimental data, to improve the systematic control accuracy and self adjustment ability, for making the rice germination to meet the technical requirements of the "fast, neat, uniform, strong", and ensure the germination rate at the same time.

\section{The Working Principle Of The Rice Sprouting}

The rice germination is a measure that makes seeds early germination under a suitable environmental condition by controlling the parameters of temperature, moisture, oxygen. The process of rice germination has two operation periods, soaking operation period and germination operation period. They can be regarded as a control process of mutual independence, and the technological requirements also quite different between each other.

During the soaking operation period, the seeds need to be putted in water with a temperature of $10^{\circ} \mathrm{C} \sim 12^{\circ} \mathrm{C}$, and the times of soaking should according to the status whether the seed absorb enough water to judgment. The standard contains that the seed will become transparence, the rice belly becomes white and visible. When stripped of the shell, the rice seed is easy to break and crush suggesting that seeds have absorbed enough water generally soaking 6 7 days, of course, the soaking time also according to the varieties of seeds. After soaking seeds, we can directly germination rather than elutriation when the seeds have coating. In this process, due to the seeds is immersed in the water all the time, thus the temperature was controlled at a constant temperature. And the temperature using the traditional PID control can meet the process requirements.

During the germination operation period, there are two progresses: seeds broken its chest and common germination. The chest breaking process needs a high temperature, experimental results show that the best temperature for it was $32^{\circ} \mathrm{C}$. And time also should not be too long, to avoid the nutrients in seeds were consumed excessively. Temperature and humidity in the germination box need to be rapidly adjust after seeds breaking chest, and when the temperature was reduced to $27^{\circ} \mathrm{C} \sim 29^{\circ} \mathrm{C}$, starting constant temperature of germination. In the whole process, the key to guarantee the quality of the rice germination is to keep the temperature in box homogeneous distribution.

Most areas of Heilongjiang agricultural areas are using the germination method of water immersion which concentrated soaking [6-7]. It can be seen in Figure 1, the circulation and heating system of rice germination mainly conclude the germination box, pump and electrical heater, and so on.

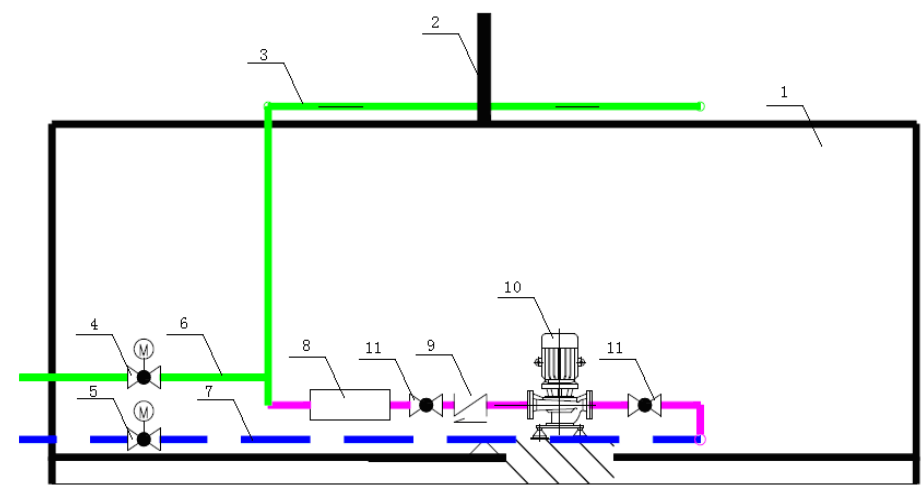

1.Germinating Box 2. Support 3. Spray Pipe 4. Water Injection Valve 5. Backwater Valve 6. Water Injection Pipe 7. Return Pipe 8. Electric Heater 9. Check Valve 10. Variable Frequency Pump 11. Manual Valve

Figure 1. Kinds of Boxes from the Circulation and Heating System 
In this system, the resistance stick was used to be a heat source of the heater. It transmits heat through water medium, to control the temperature rise and down. During the process of germination, the warm water was only retained about $15 \mathrm{~cm} \sim 20 \mathrm{~cm}$. The germination box water self circulation was completed through variable-frequency pump, and using the spray tube to spray on walls of the germination box, thus it can also achieve the regulation control to keep temperature and humidity. Therefore, the temperature and humidity were closely coupled in the progress of rice germination.

It can be found that The controlled key of the system is to complete the temperature control, and ensure the temperature homogenous distribution in the whole germination process, to avoid the local temperature is too high or too low, for guaranteeing the quality of rice germination through the analysis of the principle of soaking and germinating process.

\section{The Mathematical Modeling in Germination Process}

As a special single hidden layer neural network, RBF neural network has the advantages of simple structure, easy training and quick convergence speed of learning. So it widely used in engineering field of pattern recognition, target prediction and interpolation function at present [8]. But some disadvantages were existed in the application of RBF neural network primary algorithm, such as the experiment given of radial basis function density parameters, and the experience selected of hidden layer units number determined [9-11].

In the hidden layer of RBF neural network, the output of the $\mathrm{j}$ can be written as:

$$
\alpha_{j}(x)=\psi_{j}\left(\left\|x-c_{j}\right\| / \sigma_{j}\right)=e^{-\frac{\left\|x-c_{j}\right\|^{2}}{\sigma_{j}^{2}}}
$$

Where ${ }^{x}$ is input variable of $\mathrm{n}$ dimension, ${ }^{{ }}{ }$is the centre of ${ }^{j}$ the hidden nodes, $\|\cdot\|$ means 2-norm whose usually take the Euclidean norm, ${ }^{\psi(\cdot)}$ is RBF function whose is also a radial basis function and usually selected as Gaussian basis function.

RBF network input layer can complete a kind of nonlinear mapping, the output layer and the hidden layer nodes are a linear combination. Consequently, the relationship is as follows:

$$
y_{k}=\sum_{j}^{N} w_{k j} \alpha_{j}(x)-\theta_{k} \quad k=1,2, \cdots, r
$$

Where ${ }^{w_{k j}}$ is the connection weights from ${ }^{\alpha_{j}(x)}$ to ${ }^{y_{k}}, \theta_{k}$ is threshold value of the output node. The corresponding weighting values of ${ }^{w_{k j}}$ can be modified only when $\alpha_{j}(x)$ is larger than some numerical value.

Considering the germination process of seeds is more complexity and nonlinearity than soaking process. Therefore, the modeling method based on RBF neural network in the germination process. The three-layer feed-forward networks in RBF neural network have three important parameters, and the three parameters of RBF neural network can be optimized by genetic algorithm. That is to say, the center value ${ }^{c_{j}}$, the breadth ${ }^{\sigma_{j}}$ and the weight ${ }^{w_{i}}$ of radial basis function were carried out global optimization, to optimize on the number of hidden layer nodes, the center nodes, the weights and the thresholds of RBF neural network. 


\subsection{Collecting and Processing of Experiment Data}

The data collection times of germination process was from 11:10 to 22:40 on April 12, 2014. And the water-recycling temperature at $35^{\circ} \mathrm{C} \sim 40^{\circ} \mathrm{C}$ can make the seeds budding early, then the temperature were controlled between $25^{\circ} \mathrm{C} \sim 31^{\circ} \mathrm{C}$. The standards of spray water temperature were controlled at $32^{\circ} \mathrm{C}$, to ensure the box has a balanced temperature and enough oxygen supply, which are advantageous to budding. The mathematical modeling of sprouting stage need to collect the sample data, thus it is more complex than soaking stage. This experiment collected data of 240 groups, totally. These data contain not only environmental temperature, opening of heater valve and water temperature in the box, but also include opening of spray ball valve.

First of all, all the data were carried on normalization processing:

$$
y_{i}=\frac{x_{i}-0.95 x_{i \min }}{1.05 x_{i \max }-0.95 x_{i \min }}
$$

Where ${ }^{y_{i}}$ is a value after normalization, the scope is $[0,1] ;{ }^{x_{i}}$ is measured value; $x_{i \max }$ is the maximum of measured value; ${ }^{x_{i \min }}$ is the minimum of measured value. The normalization data were listed in Table 1.

Table 1. Part of the Normalized Test Data

\begin{tabular}{lllllll}
\hline \multirow{2}{*}{ Parameters } & \multicolumn{7}{l}{ Part of the normalized data } \\
\cline { 2 - 7 } & No.1 & No.2 & No.3 & No.4 & No.5 & No.6 \\
\hline Opening of Heater Valve & 0.025 & 0.407 & 0.832 & 0.033 & 0.043 & 0.043 \\
Environment Temperature & 0.321 & 0.240 & 0.352 & 0.604 & 0.731 & 0.521 \\
Opening of Spray Valve & 0.254 & 0.287 & 0.054 & 0.589 & 0.476 & 0.532 \\
Spray Temperature & 0.783 & 0.925 & 0.744 & 0.630 & 0.451 & 0.316 \\
Pipe Temperature & 0.250 & 0.212 & 0.219 & 0.242 & 0.253 & 0.269 \\
Temperature Point 1 & 0.246 & 0.257 & 0.253 & 0.288 & 0.3101 & 0.261 \\
Temperature Point 2 & 0.253 & 0.324 & 0.265 & 0.320 & 0.287 & 0.301 \\
\hline
\end{tabular}

\subsection{Genetic Algorithm to Optimize the Design of the RBF Network}

As a search algorithm of global optimization, genetic algorithm (GA) derived from an evolution process of biological genetic [12]. For the fitness function, it requires neither continuous or differentiability. This will become a more ideal method of setting parameters [13]. 


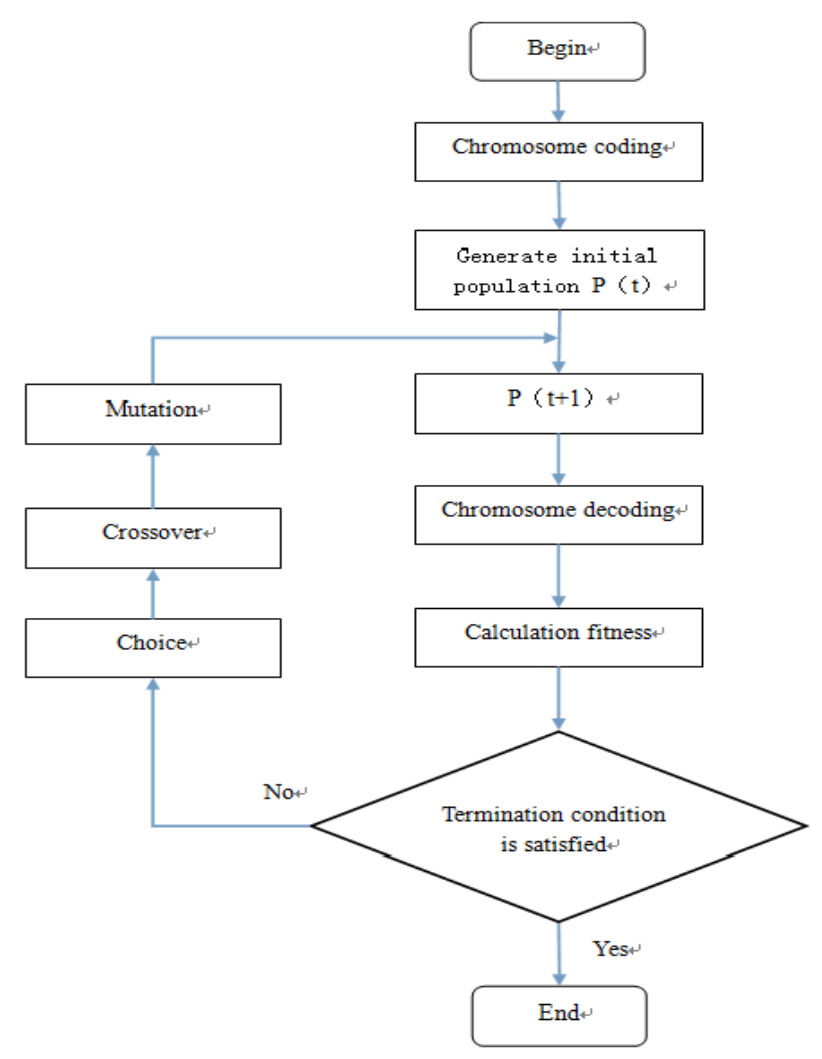

Figure 2. Genetic Algorithms Basic Flowchart

This kind three-layer feed-forward network of RBF neural network has three important parameters. They are the center of radial basis function value ${ }^{c_{j}}$, breadth ${ }^{\sigma_{j}}$ and weighting value ${ }^{w_{i}}$. Using the genetic algorithm to optimize the model of RBF neural network, it means conducting a global optimization for these three parameters. The operation is as follows:

1) Coding: The three parameters in the RBF network will be compiled into a chromosome through the form of binary string. The way of coding is as follows: the center, width and weight of the different value will be permuted in sequence, and select the number of nodes $\mathrm{P}$ of hidden layer in neural network according to the accuracy requirement of the training, to adjust $\mathrm{P}$ constantly to meet the accuracy requirement in training process.

2) The generation of initial population: The population size is 50, generally select in the scope of 20-100. Each chromosome string were randomly selected within the scope of data range, the center value of hidden layer and width were selected between $[-10,10]$, and output layer weights is between $[1,1]$. Which generate 50 chromosome strings as the initial population.

3) Fitness function structure: The training goal of the RBF neural network is to make a deviation between the expected output and the actual output of the network. That means the exact value can achieve a minimum value. Therefore, the fitness function is established as follows:

$$
\text { Fitness }=\frac{1}{\sum_{i=1}^{N} \sum_{j=1}^{K}\left(Y_{j}(i)-\bar{Y}_{j}(i)\right)^{2}}
$$


Where ${ }^{Y_{j}(i)}$ and $\bar{Y}_{j}(i)$ means actual output and desired output, respectively.

4) Selecting operation: Roulette method is the most commonly method in selecting operation.

5) Interlace operation: Under the way of real number encoding, it generated three random numbers to correspond the real numbers position of the crossover operation. Which means two new individual be generated by the linear combination of two real numbers.

6) Mutation operation: The position of the variation point position generates randomly, and then the two points mutate along the position, producing two random numbers within the scope of the parameter selection, to replace all the real number of the mutation point, and the new individual after replace as the next generation of chromosomes.

\subsection{Genetic Algorithm to Optimize the Design of the RBF Network}

The RBF neural network that based on genetic algorithm was used to build the model of the germination process, and the input amount of the network were opening of heater valve, environmental temperature, opening of spray ball valve, spray water temperature and water temperature in pipeline, respectively, to take 48 temperature points in the different positions of the seed box as the output amount of the network. The former 120 groups data were regarded as the training sample set of the neural network, and the later 120 groups data were regarded as the test data set to build the model, they both through the normalized processing of the input and output data of 240 groups. The least-square method were used to calculate the output weight value of the RBF network, and the expansion constant of the basis function constant adopt the trial and error method, the value is 0.84 , then the ${ }^{\mu+1}$ evolutionary strategy was used to optimize the number of nodes and the center at hidden layer. The number of parent is 10 , each parent individual can produce 9 offspring individuals, and each parameter is a 16-bit binary string, the population size of selection is 20 , using the adaptive mutation method, the maximum evolution algebra is 200 . The end conditions are the average fitness of continuous three generations population less than $3 \times 10^{-15}$ or reach the maximum evolution algebra, the maximum and minimum probability of variation are 0.3 and 0.8 , and extension constant of hidden layer center is 0.84 , the fitness function curve is shown in Figure 3. Thus it can be seen that the change trend of average fitness value is rising, gradually, and then tend to be the best fitness value.

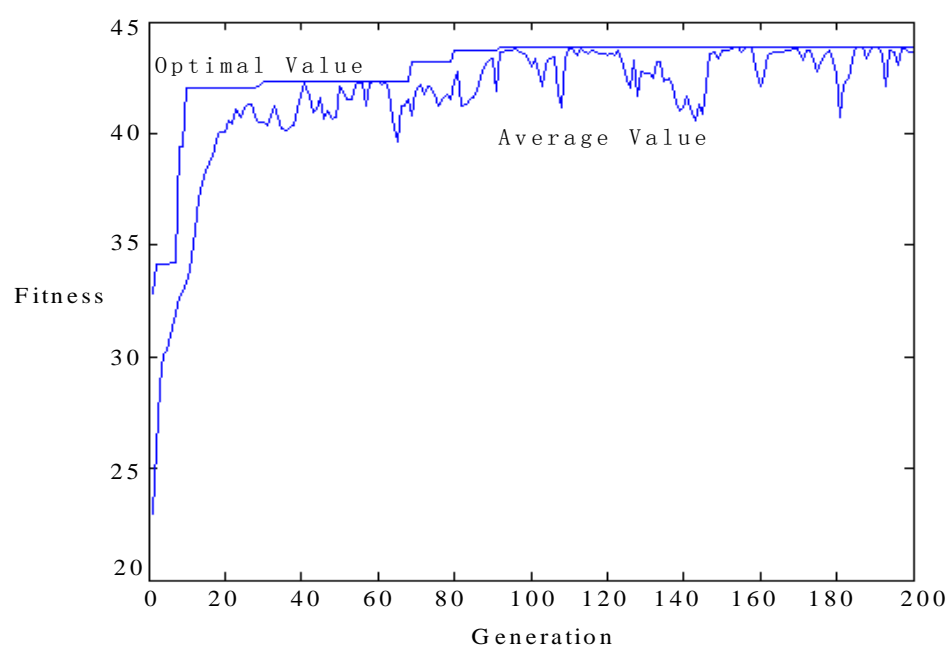

Figure 3. Group Fitness Evolution Curve 
The RBF network model that based on genetic algorithm chose 50 hidden layer nodes. The test curve of the seeds box temperature is shown in Figure 4, and the temperature error curve is shown in Figure 5.

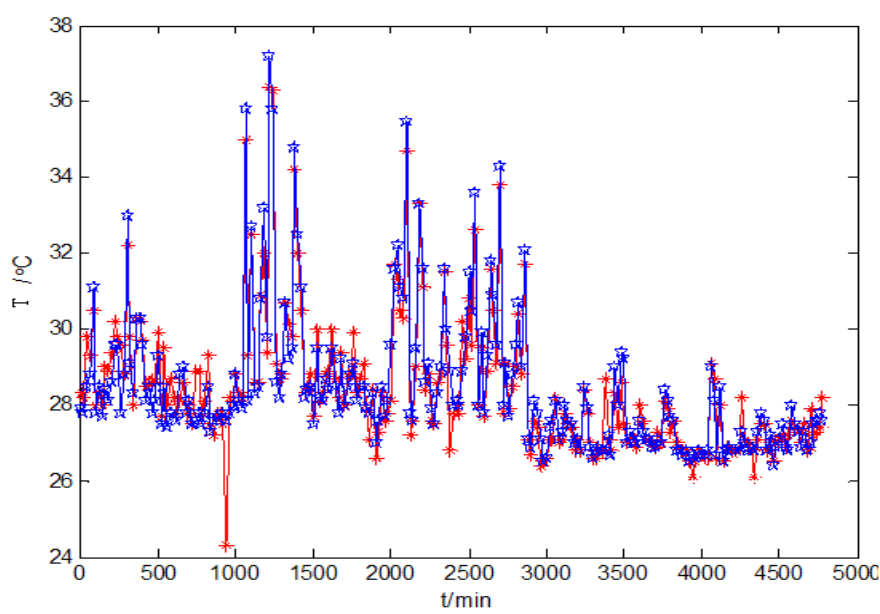

Figure 4. Temperature Curve Fitting

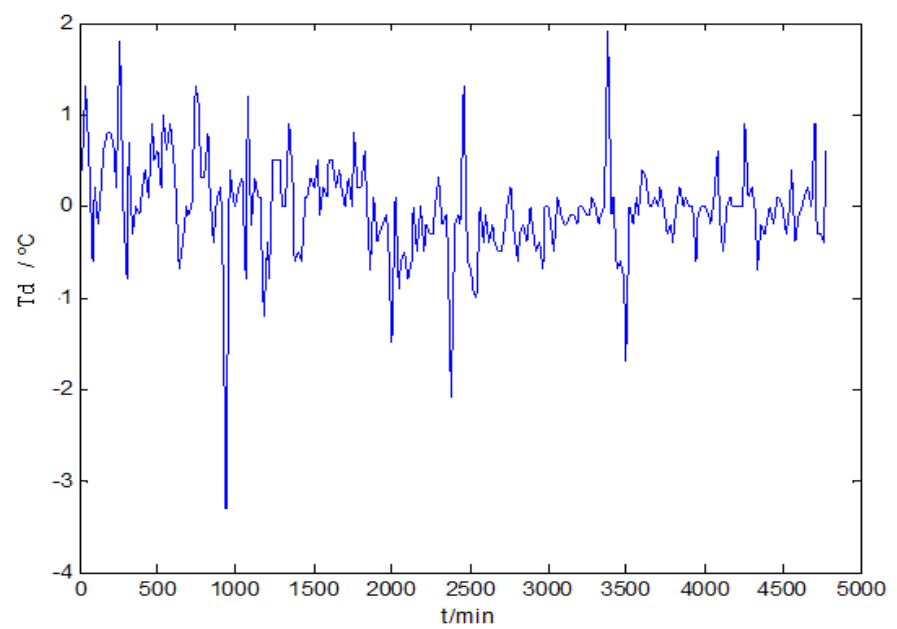

Figure 5. Temperature Error Curve

It can be seen in the figure, the temperature deviation is $\mathrm{Td}$, and can meet the accuracy requirement of the system only when the temperature test error range is $\left[-3.152^{\circ} \mathrm{C}\right.$, $1.962^{\circ} \mathrm{C}$ ], the average value of the temperature test error is $0.137^{\circ} \mathrm{C}$ and root mean square error of the temperature is $0.2157^{\circ} \mathrm{C}$.

\section{The Control Of Fuzzy-PID}

The key problem is the setting of PID parameters in the design of conventional PID controller [14-15]. But for the nonlinear system, the property of self-adaptability, robustness performance and so on, which often can not meet the requirement of the system performance [16-17].The fuzzy logic control method were applied to set the three parameters of PID, in the process of setting, using the triangle as fuzzy membership function, and the bottom margin distribute, uniformly. Furthermore, assume that the curve of the membership function is axisymmetric, the discourse universe of the deviation and the change rate of deviation fields are both set as $[1,1]$ in the membership function, and defined seven fuzzy subset, respectively. Then according to the above 
method of the composition inference and the solution defuzzification, there are total $7 \times 7=49$ fuzzy rules can be obtained in Table 2 . It can be seen in the rule table that the rules were obtained according to the logical results of experiment.

Table 2. Fuzzy Control Rule

\begin{tabular}{|c|c|c|c|c|c|c|c|c|}
\hline & \multirow{2}{*}{$\mathrm{U}$} & \multicolumn{7}{|c|}{$\mathrm{E}$} \\
\hline & & NB & NM & NS & $\mathrm{ZO}$ & PS & $\mathrm{PM}$ & PB \\
\hline & NB & PB & PB & $\mathrm{PM}$ & PM & PS & $\mathrm{ZO}$ & $\mathrm{ZO}$ \\
\hline \multirow{6}{*}{$\mathrm{EC}$} & NM & $\mathrm{PB}$ & PB & $\mathrm{PM}$ & PS & PS & $\mathrm{ZO}$ & NS \\
\hline & NS & PM & $\mathrm{PM}$ & PM & $\mathrm{ZO}$ & $\mathrm{ZO}$ & $\mathrm{ZO}$ & $\mathrm{NM}$ \\
\hline & $\mathrm{ZO}$ & PM & $\mathrm{PM}$ & PS & $\mathrm{ZO}$ & NS & NS & $\mathrm{NM}$ \\
\hline & PS & PS & PS & $\mathrm{ZO}$ & NS & NS & $\mathrm{NM}$ & $\mathrm{NM}$ \\
\hline & PM & PS & PS & $\mathrm{ZO}$ & $\mathrm{ZO}$ & NM & NM & NB \\
\hline & PB & $\mathrm{ZO}$ & NS & NS & NM & NM & NB & $\mathrm{NB}$ \\
\hline
\end{tabular}

In the Table 2, seven fuzzy subset were set as "maximum of positive direction( $P B$ )", "median of positive direction( $P M$ )", "minimum of positive direction( $P S$ )", "zero( $Z O$ )", "minimum of negative direction( $N S$ )", "median of negative direction( $N M$ )", "maximum of negative direction( $N B$ )", respectively. As shown in Table 2, the 49 fuzzy rules can be described as follows:

$$
\begin{aligned}
& R_{1}: \text { If } E \text { is } N B \text { and } E C \text { is } N B \text {, then } u \text { is } P B ; \\
& R_{2}: \text { If } E \text { is } N B \text { and } E C \text { is } N M \text {, then } u \text { is } P B ; \ldots \ldots \\
& R_{49}: \text { If } E \text { is } P B \text { and } E C \text { is } P B \text {, then } u \text { is } N B .
\end{aligned}
$$

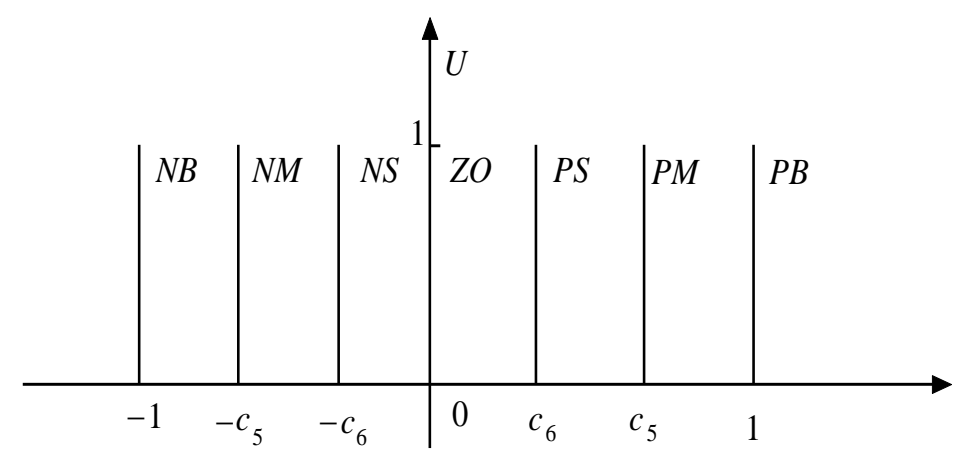

Figure 6. U Membership Function Curve

We assume that the membership function curve of the control quantity $U$ is single point type as shown in Figure 6, and it is still an axisymmetric curve. Then the accurate value can be obtained by the weighted average method.

Consequently, as shown in Figure 7, the mean square error of the seeds box temperature in the process of soaking and germination were controlled by the fuzzy-PID algorithm, the distribution range of visible mean square deviation is [0, 0.045]. This greatly shrank the difference of each temperature points. Obviously, the fuzzy-PID control can be used to control the soaking and germination of rice seeds box, and through 
this method we can meet the control requirements of higher temperature.

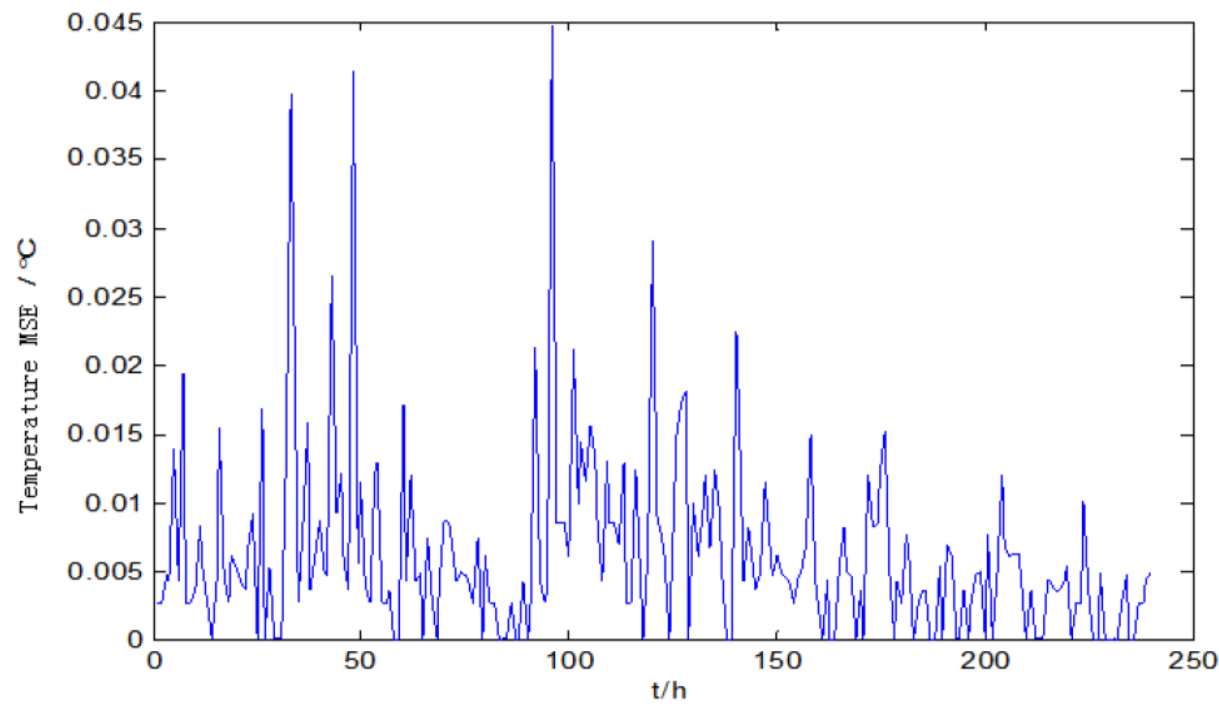

\section{Figure 7. Mean Square Error Curve of Box Temperature of Fuzzy - PID Control}

But considering the mean square error of each point temperature cannot to explain all the uniformity of al temperature point distribution, enough. So the temperature of the 48 points in seeds box can be obtained only by the control strategy of the fuzzy-PID. As shown in Figure 8, the curved surface of each temperature points in peregrination process were exhibited by the three-dimensional curved surface chart in Matlab.

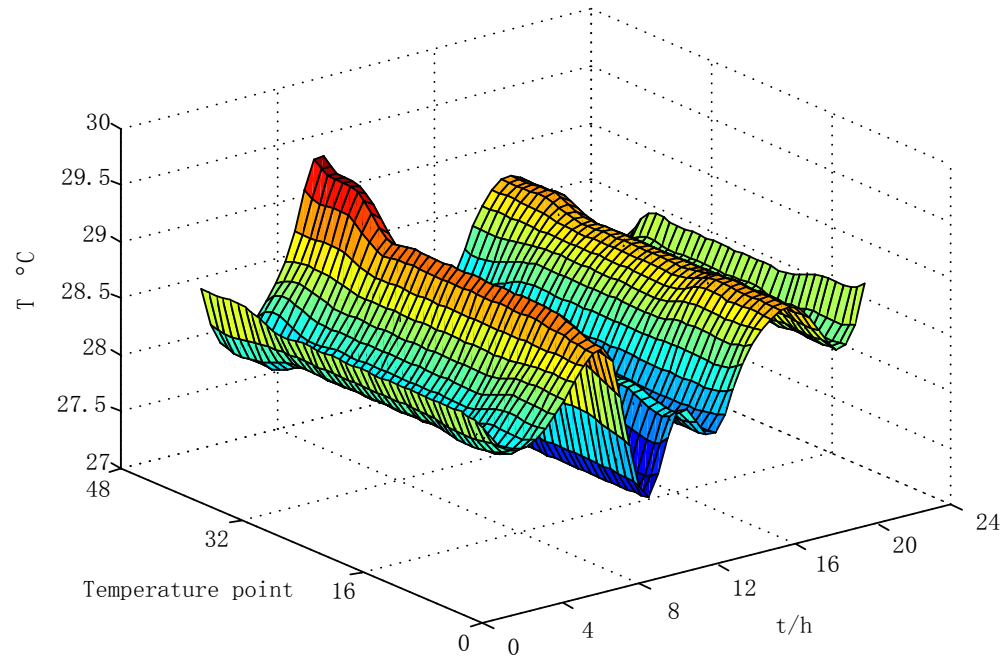

Figure 8. Sprouting Process Temperature Point Distribution Surface Chart

It can be seen in the Figure, the temperature field of the germination process is uniformly distributed, and the curved surface of temperature points is basically maintain between $27.5^{\circ} \mathrm{C} \sim 29.5^{\circ} \mathrm{C}$. It completely meets the temperature requirements in the germination process. 


\section{Experimental Verification}

It is proved by Matlab Simulation, the effectiveness of the proposed control scheme. Using rice seed sprouting test bench make the system complete an accelerating seed germination process. In the experimental conditions for the heating valve opening $0.477,11^{\circ} \mathrm{C}$ Environment temperature, spray ball valve opening 0.267 , spray water temperature $41^{\circ} \mathrm{C}$, pipeline water temperature within $32^{\circ} \mathrm{C}, 48$ points of temperature evenly distributed between the layers, the accelerating seed germination process of the Kongyu 131 experiment research. The test performance indicators are shown in Table 3:

\section{Table 3. Performance Indexes of Verification Test}

\begin{tabular}{lcc}
\hline Varieties & Budding rate & Budding uniformity \\
\hline Kongyu131 & $94.8 \%$ & $95 \%$ \\
\hline
\end{tabular}

The rice varieties performance indicators of the Kongyu 131 show that the data obtained by the verification test of combined control of PID and fuzzy-PID are close to the expected value and can meet the technical requirements, which is obtained through the verification experiment.

\section{Conclusion}

In rice germination process, this paper used the RBF neural network to conduct a system modeling, and optimized the network parameters through the genetic algorithm. The optimized system model through the simulation study can guarantee the temperature test error range between $\left[-3.152^{\circ} \mathrm{C}, 1.962^{\circ} \mathrm{C}\right]$. The average value of the temperature test error is $0.137^{\circ} \mathrm{C}$, and the root mean square error is $0.2157^{\circ} \mathrm{C}$. They all reach the accuracy requirements of the system. The uniform distribution of temperature in the soaking and germination box was realized by fuzzy-PID control method, and the experiment show that this method can improve the sprouting rate of rice. This will provide a reliable guarantee for the later production of the rice germination.

\section{Acknowledgments}

This work is supported by the Fostering Plan of Heilongjiang Bayi Agricultural University (Grant No.XZR2014-13).

\section{References}

[1] S. Gu, "Synchronous Germination of Rice Seed Soaking Method", China Rice, vol. 8, no. 4, (2002), pp. 29.

[2] X. Xu, "Soaking and Pregermination Technique of Rice Seed", Seed Science \&Technology, vol. 29 , no. 8, (2009), pp. 33-34.

[3] F. Zhang, S. Yi, Y. Liu and K. Liu, "Design of Temperature and Water Level Control System for Rice Seed Germination Box", vol. 36, no. 12, (2014), pp. 34-37.

[4] J. Shi, H. Cao and F. Tan, "Design of Soaking Germination Automatic Monitoring System Based on PLC", Journal of Agricultural Mechanization Research, vol. 35, no. 8, (2013), pp. 192-195.

[5] G. Tao, S. Yi, Z. Li and D. Shi, "Temperature Field Analysis of Water Immersion Temperature Rice Seed Soaking Germination Equipment", Transactions of the Chinese Society for Agricultural Machinery, vol. 42, no. 10, (2011), pp. 90-95.

[6] X. Mao, S. Yi, L. Yu and D. Shi, "Design on Large-Scale Concentrated Soaking Germination Equipment in Intelligent Temperature Control For Rice", Journal of Heilongjiang Bayi Agricultural University, vol. 23, no. 2, (2011), pp. 66-68.

[7] B. Wang, Y. Bao and C. Fan, "The Research of the Heat Preservation and the Heating System of the Paddy Rice Presoaking and Germination Greenhouse", Journal of Agricultural Mechanization Research, vol. 30, no. 9, (2008), pp. 66-68.

[8] X. Zheng, Q. He and Y. Fei, "The Safety State Model Identification of Tower Crane Based on RBF 
Neural Network and Uniform Design”, Machinery Design \& Manufacture, vol. 1, no. 1, (2005), pp. 7880

[9] X. Hou, Y. Hu, Y. Li and X. Xu, "Rational Structure of Multilayer Artificial Neural Network", Journal of Northeastern University: Natural Science, vol. 24, no. 1, (2003), pp. 35-38.

[10] N. A. Magnitskii, "Some New Approaches to the Construction and Learning of Artificial Neural Networks", Computational Mathematics and Modeling, vol. 12, no. 4, (2001), pp. 293-304.

[11] S. W. Choi, D. Lee and J. H. Park, "Nonlinear regression using RBFN with linear submodels", Chemometrics and Intelligent Laboratory Systems, vol. 65, no. 2, (2003), pp. 191-208.

[12] C. Guo, Y. Wang and X. Wang, "The optimization of PID parameter for hydraulic servo system based on genetic algorithm", Machine Tool \& Hydraulics, no. 8, (2004), pp. 14-16.

[13] C. Liang P. Lü, J. Ji and X. Wang, "Optimization of PID Parameters for Electro- hydraulic Variable Rate Fertilization System Based on Genetic Algorithm", Transactions of the Chinese Society for Agricultural Machinery, vol. 44, supp. 1, (2013), pp. 89-93.

[14] S. Gao, X. Gao and Z. Zhu, "Stripper Temperature Control Method Based on Variable Universe Fuzzy-PID”, Journal of Northeastern University(NaturalScience), vol. 31, no. 10, (2010), pp. 13691372.

[15] H. Tang, Z. Li, Z. Wang, X. Zhang and Y. Su, “A fuzzy PID control system”, Electric Machines And Control, vol. 9, no. 2, (2005), pp. 136-138.

[16] X. Wang, H. Sun and D. Zhang, "The Fuzzy-PID Control Design and Dynamic Simulation for Dynamometers", Journal of Harbin University of Science and Technology, vol. 14, no. 2, (2009).

[17] P. Rong, R. Dai and G. Fu, "Fuzzy Control Systems Based on the Variable Universe and Changing Fuzzy Rules", Journal of Harbin University of Science And Technology, vol. 11, no. 5, (2006), pp. 3436. 
International Journal of Control and Automation Vol. 9, No. 4 (2016) 